\title{
Smartphone Apps Targeting Physical Activity in People With Rheumatoid Arthritis: Systematic Quality Appraisal and Content Analysis
}

Lindsay M Bearne ${ }^{1 *}$, MCSP, MSc, PhD; Mandeep Sekhon ${ }^{1 *}$, BSc, MSc, PhD; Rebecca Grainger ${ }^{2 *}$, BMedSci, MBChB, FRACP, PhD; Anthony $\mathrm{La}^{1 *}$, BSc, MSc; Mehrdad Shamali ${ }^{1 *}, \mathrm{BSc}, \mathrm{MSc}$; Aliya Amirova ${ }^{{ }^{*}}, \mathrm{BSc}, \mathrm{MSc}$; Emma L Godfrey $^{1 *}$, BA, MA, PhD; Claire M White ${ }^{1 *}, \mathrm{BSc}, \mathrm{MSc}, \mathrm{PhD}$

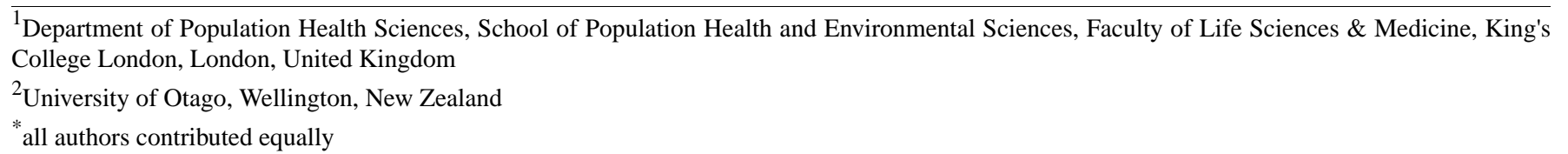

\section{Corresponding Author:}

Lindsay M Bearne, MCSP, MSc, PhD

Department of Population Health Sciences, School of Population Health and Environmental Sciences

Faculty of Life Sciences \& Medicine

King's College London

2nd Floor, Addison House, Guy's Campus

London, SE1 1UL

United Kingdom

Phone: 4402078486283

Email: lindsay.bearne@kcl.ac.uk

\section{Abstract}

Background: Rheumatoid arthritis (RA) is a disabling, inflammatory joint condition affecting $0.5 \%-1 \%$ of the global population. Physical activity (PA) and exercise are recommended for people with RA, but uptake and adherence tend to be low. Smartphone apps could assist people with RA to achieve PA recommendations. However, it is not known whether high quality, evidence-informed PA apps that include behavior change techniques (BCTs) previously identified as effective for PA adherence are available for people with RA.

Objective: This study aims to systematically identify apps that include goals to facilitate PA for adults with RA and assess app quality and content for the inclusion of relevant BCTs against recommendations for cardiorespiratory, resistance, flexibility, and neuromotor PA and exercise.

Methods: A systematic search of the Apple App Store and Google Play Store in the United Kingdom was conducted to identify English language apps that promote PA for adults with RA. Two researchers independently assessed app quality (mobile app rating scale [MARS]; range 0-5) and content (BCT Taxonomy version 1, World Health Organization, the American College of Sports Medicine, and the European League against Rheumatism recommendations for PA). The completeness of reporting of PA prescription was evaluated using a modified version of the Consensus on Exercise Reporting Template (CERT; range 0-14).

Results: A total of 14,047 apps were identified. Following deduplication, 2737 apps were screened for eligibility; 6 apps were downloaded ( 2 on the Apple App Store and 4 on the Google Play Store), yielding 4 unique apps. App quality varied (MARS score 2.25-4.17). Only 1 app was congruent with all aspects of the PA recommendations. All apps completely or partially recommended flexibility and resistance exercises, 3 apps completely or partially advised some form of neuromotor exercise, but only 2 offered full or partial guidance on cardiorespiratory exercise. Completeness of exercise reporting was mixed (CERT scores 7-14 points) and 3-7 BCTs were identified. Two BCTs were common to all apps (information about health consequences and instruction on how to perform behavior). Higher quality apps included a greater number of BCTs and were more closely aligned to PA guidance. No published trials evaluating the effect of the included apps were identified.

Conclusions: This review identifies 4 PA apps of mixed quality and content for use by people with RA. Higher quality apps were more closely aligned to PA guidance and included a greater number of BCTs. One high-quality app (Rheumatoid Arthritis 
Information Support and Education) included 7 BCTs and was fully aligned with PA and exercise guidance. The effect of apps on PA adherence should be established before implementation.

(JMIR Mhealth Uhealth 2020;8(7):e18495) doi: $\underline{10.2196 / 18495}$

\section{KEYWORDS}

rheumatoid arthritis; physical activity; exercise; mobile applications; behavior change techniques; mobile phone

\section{Introduction}

\section{Background}

Rheumatoid arthritis (RA) is a disabling, autoimmune inflammatory condition that affects $0.5 \%$ to $1 \%$ of the global population [1,2]. Evidence-informed guidelines recommend physical activity (PA) and exercise for people with RA tailored to an individual's baseline PA level, disease activity, and symptoms. PA prescriptions comprise exercise type (ie, cardiorespiratory, resistance, flexibility, or neuromotor training), the number of sets/repetitions, load and/or intensity, recovery time/method of progression, and frequency and duration of exercise sessions [3-7].

However, people with RA tend not to meet the recommended levels of PA [8,9], and there are several barriers that can make changing PA behavior challenging for people with RA without appropriate support and guidance [8-11].

Interventions that target the factors that influence adherence to PA using behavior change techniques (BCTs; ie, strategies that help an individual change their behavior) can improve PA levels and health outcomes [12-14]. Many people with RA would like help to increase their PA from health care professionals [9], but interventions can be difficult to implement due to lack of time, resources, and/or the limited number of appropriately trained health care professionals [15-17]. Consequently, novel methods of delivering interventions that can be tailored for people with RA are needed to support adherence to PA.

With the rapid increase in the availability of mobile apps [18], the development and use of high-quality apps may be a promising approach to support people with RA to reach evidence-informed PA recommendations. However, appraisals of apps for RA symptom monitoring and self-management, including PA, suggested that app quality and content were heterogeneous and they did not consistently provide evidence-based management strategies or include validated symptom measures [19-22]. Apps were seldom developed in collaboration with people with RA or clinicians, and older adults often found them difficult to use [21-23].

The effects of digital interventions on PA adherence in people with RA are unclear. A systematic review of randomized controlled trials (4 trials; $n=492$ participants) found limited evidence of an effect of interactive digital interventions (ie, interactive information and communication technologies to support behavior change, such as online fora) on PA adherence in people with RA or juvenile idiopathic arthritis [24]. Trials included 3 to 9 BCTs [24]. No quality rating of the interactive digital interventions using standardized measures was conducted. Thus, the systematic identification and evaluation of apps that can support adherence to PA and evidence to support the effectiveness of these apps are required.

Recommendations suggest that the safety, quality, and content of self-management apps (including PA apps) for people with RA should be considered during all stages of development, evaluation, and implementation [25]. Features such as engagement, esthetics, functionality, and information quality should be assessed using reliable tools, such as the mobile app rating scale (MARS) [26]. Content should be evaluated for (1) BCTs using a recognized framework (eg, BCT Taxonomy version 1, BCTT v1) [27], (2) congruence with evidence-informed recommendations on PA (eg, World Health Organization and the European League against Rheumatism) $[3,5]$ and exercise (eg, American College of Sports Medicine) $[4,6,28]$, and (3) described using standardized reporting formats such as the Consensus on Exercise Reporting Template (CERT) [7,29].

\section{Objectives}

This study aims to systematically identify and evaluate the quality and content of publicly available mobile apps aiming to support the uptake of and adherence to PA in people with RA.

\section{Methods}

\section{Protocol and Registration}

The review protocol was developed a priori by a team consisting of physiotherapists, rheumatologists, and health psychologists with experience in conducting systematic reviews, evaluating mobile health apps, PA, and behavior change interventions. The protocol was not eligible for registration on the International Prospective Register of Systematic Reviews (PROSPERO) as PROSPERO does not register reviews of apps.

\section{Data Sources}

Where possible, this review followed the Preferred Reporting Items for Systematic Review and Meta-Analyses (PRISMA) guidelines for reporting systematic reviews [30].

Systematic individual searches of the Google Play (Samsung Galaxy s8 operating G950FXXS4DSD3/ G950FOXM4DSBA/G950FXXS4DSD3 software with Android version 9) and Apple App Store (iOS 12.3.1 software operating on iPhone 7) were conducted on June 19 and 20, 2019.

Key search terms for RA, PA, and exercise were identified from the literature [22,24] and refined by all coauthors. Search terms were used in isolation and combination to search for all relevant apps (Table 1). 
To ensure that all potentially relevant apps were captured, searches for rheumatoid arthritis and arthritis were also conducted in the United Kingdom National Health Service app library and the Apple App Store in New Zealand, Australia, Canada, and United States using the fnd website [31].

Table 1. Key search terms used for identifying mobile apps targeting physical activity in people with rheumatoid arthritis.

\begin{tabular}{|c|c|c|c|c|c|}
\hline Search terms & Rheumatic & Arthritis & $\mathrm{RA}^{\mathrm{a}}$ & Rheumatoid arthritis & Inflammatory arthritis \\
\hline Physical activity & $\begin{array}{l}\text { Rheumatic physical ac- } \\
\text { tivity }\end{array}$ & $\begin{array}{l}\text { Arthritis physical ac- } \\
\text { tivity }\end{array}$ & $\begin{array}{l}\text { RA physical ac- } \\
\text { tivity }\end{array}$ & $\begin{array}{l}\text { Rheumatoid arthritis } \\
\text { physical activity }\end{array}$ & $\begin{array}{l}\text { Inflammatory arthritis } \\
\text { physical activity }\end{array}$ \\
\hline Exercise & Rheumatic exercise & Arthritis exercise & RA exercise & $\begin{array}{l}\text { Rheumatoid arthritis } \\
\text { exercise }\end{array}$ & $\begin{array}{l}\text { Inflammatory arthritis } \\
\text { exercise }\end{array}$ \\
\hline Walking & Rheumatic walking & Arthritis walking & RA walking & $\begin{array}{l}\text { Rheumatoid arthritis } \\
\text { walking }\end{array}$ & $\begin{array}{l}\text { Inflammatory arthritis } \\
\text { walking }\end{array}$ \\
\hline Strength & Rheumatic strength & Arthritis strength & RA strength & $\begin{array}{l}\text { Rheumatoid arthritis } \\
\text { strength }\end{array}$ & $\begin{array}{l}\text { Inflammatory arthritis } \\
\text { strength }\end{array}$ \\
\hline Fitness & Rheumatic fitness & Arthritis fitness & RA fitness & $\begin{array}{l}\text { Rheumatoid arthritis } \\
\text { fitness }\end{array}$ & $\begin{array}{l}\text { Inflammatory arthritis } \\
\text { fitness }\end{array}$ \\
\hline Training & Rheumatic training & Arthritis training & RA training & $\begin{array}{l}\text { Rheumatoid arthritis } \\
\text { training }\end{array}$ & $\begin{array}{l}\text { Inflammatory arthritis } \\
\text { training }\end{array}$ \\
\hline Running & Rheumatic running & Arthritis running & RA running & $\begin{array}{l}\text { Rheumatoid arthritis } \\
\text { running }\end{array}$ & $\begin{array}{l}\text { Inflammatory arthritis } \\
\text { running }\end{array}$ \\
\hline
\end{tabular}

${ }^{\mathrm{a}} \mathrm{RA}$ : rheumatoid arthritis.

\section{App Selection}

\section{Eligibility Criteria}

Deduplication based on app store title and description (provided in the read more section in the app) was conducted by 2 independent reviewers (R1 and R2), and potentially eligible apps were downloaded on one or both devices, where possible. The information section for each potentially suitable app was reviewed against the eligibility criteria. Inclusion criteria comprised (1) a smartphone-based app available in at least one app store; (2) targeted at adults ( $\geq 18$ years) with RA as users specifically, (3) focused on promoting uptake and adherence to PA or exercise, and (4) available in English. Apps were excluded if they (1) targeted people with a condition other than RA, (2) were solely for use by health care practitioners, and (3) were specific clinic, congress/conference, or product apps. No cost restrictions were applied and full app content was purchased, if required.

\section{Data Items and Extraction}

Data extraction was conducted by 2 independent reviewers (R1 and R2) using a data extraction tool developed a priori. Each app was used for at least $10 \mathrm{~min}$. The following app characteristics were extracted: app name, platform, version, developer, stakeholder involvement in app development, size, star rating, number of installs, privacy policy statements, and medical product status. The availability of published trials evaluating app efficacy or effectiveness was checked on developer websites and by searching electronic databases (last search in June 2019) using the search strategy described in our systematic review to synthesize the evidence for the effectiveness of mobile apps designed to enhance adherence to PA for people with inflammatory arthritis (PROSPEROCRD42019129341) [32]. In addition, searches in
Google, Google Scholar, and PubMed were undertaken using the app name as a search term. The review of search results was stopped after the first 50 irrelevant results.

\section{Quality Appraisal of Individual Apps}

The quality of the included apps was assessed using the simple and reliable MARS [26]. A total of 23 items were rated on a 5 -point Likert scale (1=inadequate to 5=excellent) and summarized into 4 categories: engagement (5 items), functionality (4 items), esthetics (3 items), information quality (7 items), and a subjective quality scale (4 items). The mean score for each category and the MARS total score (the mean of the 4 category scores excluding subjective quality scale) was calculated (maximum score $=5$ ). Item 19 of the MARS, evidence base, was excluded from all calculations because no apps had been studied in clinical trials, as specified by Stoyanov et al [26].

\section{Content Analysis of Individual Apps}

PA and exercise recommendations for people with RA were evaluated (yes, partial, or no) for congruence with evidence-informed guidance for cardiorespiratory, resistance, flexibility, and neuromotor PA [3-6]. This three-point scale reflected the format of the checklists used to assess the fidelity of rehabilitation and exercise intervention delivery [33-35]. Apps were considered to be fully aligned with the guidance if they included details of exercise type, intensity (eg, load, sets, repetitions), frequency, and time/duration of exercise/sessions (yes), partially aligned with guidance if they included at least one of these parameters (partial) and not aligned with the guidance if they did not include any of these parameters (no). Content was assessed against the PA guidance that was most appropriate for the age and exercise experience of the target user for each app. 
Guidance indicates that adults (aged 18 to 64 years) should perform $\geq 150 \mathrm{~min}$ of cardiorespiratory exercise at moderate intensity or $75 \mathrm{~min}$ of vigorous/high-intensity activity or an equivalent combination per week in bouts $\geq 10 \mathrm{~min}$. Adults who are novice (ie, unaccustomed to exercise) or intermediate (ie, some experience of exercise) exercisers should also perform between 2 and 4 sets of resistance exercises ( 8 and 12 repetitions per set) at a moderate/hard intensity (ie, $60 \%$ to $70 \%$ of one repetition maximum) for each major muscle group on at least two days per week. However, experienced exercisers (ie, engaged in habitual exercise) should work at a hard or very hard intensity (ie, $\geq 80 \%$ one repetition maximum). Exercises to increase or maintain flexibility are advised at least twice per week for a minimum of $10 \mathrm{~min}$. Each stretch should be held to the point of tightness or slight discomfort for 10 to 30 seconds up to a total of 60 seconds of stretching time per exercise. Adults with poor mobility and balance are advised to perform 20 to 30 min of neuromotor exercises (eg, balance, agility, coordination, proprioceptive exercise training, or multifaceted activities such as yoga) on at least two days per week to enhance physical function, balance, and prevent falls [3-5].

Guidelines for older adults ( $\geq 65$ years) and adults between 50 and 64 years with long-term conditions are similar, although activities should be tailored to health and disease status, baseline fitness, and initially comprise very light or light intensity resistance exercises (ie, $40 \%$ to $50 \%$ of one repetition maximum) and stretches of a 30- to 60-second duration $[3,5,6]$.

The CERT is a reliable, 16-item (7 domain) specification to evaluate the reporting of exercise interventions (Table 2) $[7,29,36]$. Each item was rated (yes $=1$, no $=0$, or not applicable) and summed to produce a total CERT score. It was not possible to score items 11 or 16 ; therefore, the maximum possible CERT score was 14 [7,29].

Table 2. Abbreviated item description for the Consensus of Exercise Reporting Template.

\begin{tabular}{cl}
\hline Item category and item number & Abbreviated item description \\
\hline What & Description of type of exercise equipment \\
Who & \\
How & Description of qualifications/expertise/training of instructor \\
3 & \\
4 & Description of whether exercises are performed individually or in a group \\
5 & Description of whether exercises are supervised/unsupervised \\
6 & Description of the measurement/reporting of adherence to exercise \\
7 & Description of motivational strategies \\
8 & Decision rules for determining exercise progression and how exercise was progressed \\
9 & Description of each exercise to enable replication (eg, illustrations, photos) \\
10 & Description of any home programme component \\
11 & Description of any nonexercise component \\
\hline
\end{tabular}

Where

12 Description of exercise setting

When, how much

Description of exercise intervention and dosage

Tailoring

14

15

How well

16

Description of whether exercises are generic or tailored to the individual

Decision rule for starting level of exercise
Two postgraduate physiotherapy students (R1 and R2) independently assessed app quality using the MARS and PA and exercise content for congruence with evidence-informed recommendations and reporting using the CERT. Discrepancies were resolved by discussion and another assessor acted as an arbiter if required. As recommended by the MARS developers, assessors received training on applying the MARS by viewing the MARS training video [26,37] and bespoke training to assess app content for congruence with PA recommendations and completeness of reporting by a member of the CERT development group [7].

Before rating the included apps, the assessors evaluated up to 5 randomly selected apps (identified in the search but previously 
excluded from the analysis) and discussed their results to ensure an understanding of the MARS, PA and exercise recommendations, and CERT items and processes.

The BCTT v1 is a comprehensive and reliable tool that consists of 93 distinct BCTs that can be used to identify specific active components of behavioral interventions [27]. It is used to design and retrospectively evaluate behavioral health interventions, such as PA [38].

Two postgraduate health psychologists (R3 and R4) completed the training for applying the BCTT v1 before independently coding BCTs in the included apps [27]. Discrepancies were resolved by discussion, and another rater acted as an arbiter if required.

\section{Statistical Analysis}

Interrater reliability using an intraclass correlation coefficient (ICC) was calculated using IBM SPSS version 25.0 (two-way random-effects model of absolute agreement between single ratings). Scores $<0.5$ were considered poor agreement, moderate reliability (0.5-0.75), good reliability (0.75-0.9), and excellent reliability (>0.9) [39].

Figure 1. Flow diagram illustrating the process of mobile app selection.
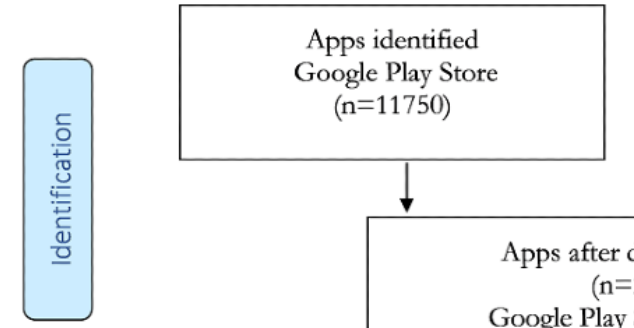$$
(n=11750)
$$
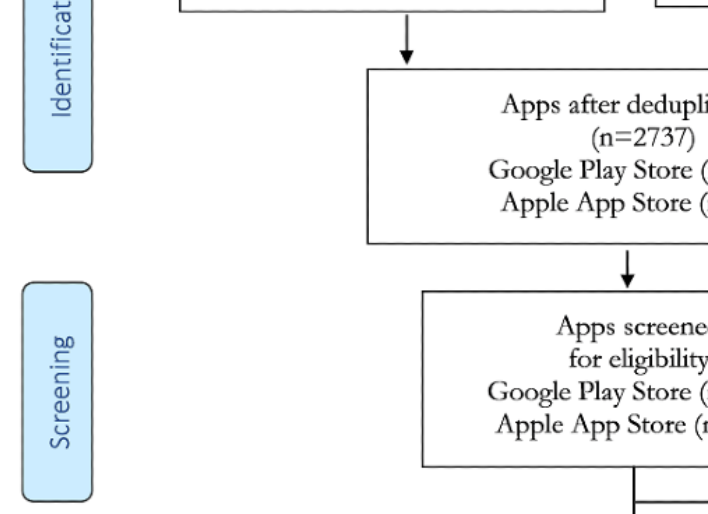

Google Play Store $(\mathrm{n}=585)$

Apple App Store $(n=2152)$
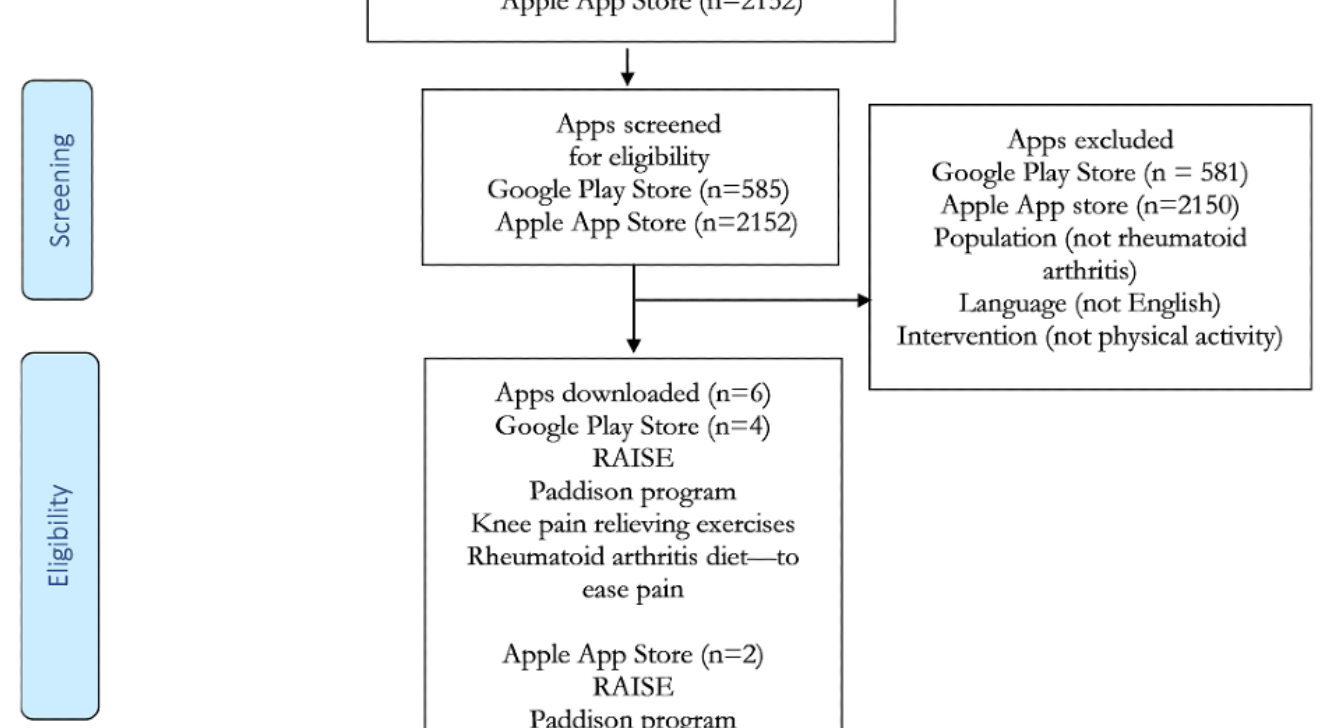

产

Google Play Store $(n=4)$ RAISE

Paddison program

Knee pain relieving exercises

Rheumatoid arthritis diet- to ease pain

Apple App Store $(n=2)$ RAISE

Paddison program

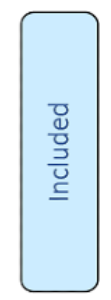

Unique apps $(\mathrm{n}=4)$

RAISE

Paddison program

Knee pain relieving exercises

Rheumatoid arthritis diet- to ease pain 


\section{Characteristics of the Included Apps}

The characteristics of the included apps are detailed in Table 3. A total of 3 apps were developed by or in conjunction with people with RA (RAISE and Paddison program) or clinicians (RAISE and Knee pain relieving exercises). Apple App store star ratings of included apps ranged from 2 (RAISE on Android) to 5 stars (RAISE on iOS), although the number of ratings was generally low (Knee pain relieving exercises $n=140$ and RAISE-iOS $n=1$ ratings). All mobile apps were free to download. The Paddison program app required a payment of
US $\$ 69$ to access the Paddison program resources and daily videos for 12 days (essential package). A fee of US \$99 provided access to all content, that is, Paddison program resources, 12 daily videos, and additional updated video/website content (advanced healing package).

The apps had been installed 500 (RAISE on Android) to 50,000 (Knee pain relieving exercises) times. None of the included apps had a medical product status. No published trials evaluating the effect of the included apps were identified.

Table 3. Characteristics and quality rating of mobile apps targeting physical activity in people with rheumatoid arthritis.

\begin{tabular}{|c|c|c|c|c|c|c|}
\hline App & Knee pain reliev- & Rheumatoid arthritis & RAISE $^{\mathrm{a}}$ & & Paddison progran & \\
\hline A platform & Android $^{\mathrm{b}}$ & Android $^{\mathrm{b}}$ & Android & iOS & Android & iOS \\
\hline Developer & Dr Kavin Khatri & TP Topics & Publicis Dublin & Publicis Dublin & $\begin{array}{l}\text { Paddison pro- } \\
\text { gram }\end{array}$ & $\begin{array}{l}\text { Paddison pro- } \\
\text { gram }\end{array}$ \\
\hline $\begin{array}{l}\text { Stakeholder involvement in } \\
\text { app development }\end{array}$ & Clinician & $\mathrm{N} / \mathrm{A}^{\mathrm{c}}$ & $\begin{array}{l}\text { Patient organiza- } \\
\text { tion and clinicians }\end{array}$ & $\begin{array}{l}\text { Patient organiza- } \\
\text { tion and clinicians }\end{array}$ & $\begin{array}{l}\text { Patient represen- } \\
\text { tative }\end{array}$ & $\begin{array}{l}\text { Patient represen- } \\
\text { tative }\end{array}$ \\
\hline Version & 1.0 .0 & 1.1 .2 & 1.1 .2 & 1.0 .0 & 1.2 .0 & 2.1 .0 \\
\hline Size, $\mathrm{MB}^{\mathrm{d}}$ & 4.84 & 16.27 & 10.18 & 18.90 & 36.31 & 48.80 \\
\hline $\begin{array}{l}\text { Star rating (number of rat- } \\
\text { ings) }\end{array}$ & $4.0(140)$ & $3.0(3)$ & $2.0(2)$ & $5.0(1)$ & $4.4(8)$ & $-^{\mathrm{e}}$ \\
\hline Number of installations & $>50,000$ & $>1000$ & $>500$ & - & $>1000$ & - \\
\hline $\begin{array}{l}\text { Privacy policy statement } \\
\text { (yes/no) }\end{array}$ & Yes & Yes & Yes & Yes & Yes & Yes \\
\hline $\begin{array}{l}\text { Medical product status } \\
\text { (yes/no) }\end{array}$ & No & No & No & No & No & No \\
\hline $\begin{array}{l}\text { Peer-reviewed publications } \\
\text { (yes/no) }\end{array}$ & No & No & No & No & No & No \\
\hline MARS ${ }^{\mathrm{f}}$-engagement & 2.00 & 2.40 & 3.90 & 3.90 & 3.70 & 3.70 \\
\hline MARS-functionality & 4.50 & 3.12 & 4.38 & 4.38 & 3.88 & 3.88 \\
\hline MARS-esthetics & 2.33 & 3.00 & 4.33 & 4.33 & 3.66 & 4.00 \\
\hline MARS-information & 2.83 & 2.83 & 4.08 & 4.08 & 3.33 & 3.33 \\
\hline MARS-subjective & 1.88 & 2.84 & 3.25 & 3.25 & 2.00 & 2.00 \\
\hline MARS-total & 2.92 & 2.83 & 4.17 & 4.17 & 3.64 & 3.73 \\
\hline
\end{tabular}

${ }^{a}$ RAISE: Rheumatoid Arthritis Information Support and Education.

${ }^{\mathrm{b}}$ Apps not available on the iOS platform.

${ }^{\mathrm{c}} \mathrm{N} / \mathrm{A}$ : not applicable.

${ }^{\mathrm{d}}$ MB: megabytes.

e Data not available.

${ }^{\mathrm{e}}$ MARS: mobile app rating scale.

\section{Quality Appraisal of the Included Apps}

The MARS total score ranged from 2.83 (Rheumatoid arthritis diet- to ease pain) to 4.17 (RAISE), indicating variation in app quality (Table 3 ). The esthetics category showed the greatest variability (2.30 for Knee pain relieving exercises to 4.33 for RAISE). A total of 3 of the 4 apps (Knee pain relieving exercises, Rheumatoid arthritis diet-to ease pain, and RAISE) scored their highest MARS score for the functionality category and their lowest MARS score for the engagement category. The

Paddison program achieved its highest score for esthetics on the iOS platform but not the Android platform. This is because some items (eg, logos) were distorted or not visible on the Android platform. The Paddison program achieved its lowest score for the information quality category on both platforms.

Only 1 app (RAISE) was rated $>4$ out of 5 for the MARS total score and achieved the highest score in all categories (ie, engagement, esthetics, information, subjective) except 
functionality. The Knee pain relieving exercise app scored highest for functionality.

The interrater reliability for the MARS indicated excellent agreement for all subscales: engagement (ICC 0.96; 95\% CI 0.71-0.99), functionality (ICC 0.92; 95\% CI 0.01-0.99), esthetics (ICC 1.00 absolute agreement), information (ICC 0.95; 95\% CI 0.64-0.99), subjective (ICC 0.98; 95\% CI 0.83-0.99), and the MARS total score (ICC 0.99; 95\% CI 0.92-0.99).

\section{Content Analysis of the Included Apps}

The content of the included apps is summarized in Tables 4 to 6. All apps completely or partially recommended flexibility and resistance exercises. Three apps completely or partially advised some form of neuromotor exercise (Rheumatoid arthritis diet - to ease pain, RAISE, and Paddison program). Two apps offered full or partial guidance on cardiorespiratory exercise (Rheumatoid arthritis diet— to ease pain and RAISE; Table 4).

Only 1 app (RAISE) was congruent with all aspects of the evidence-informed PA recommendations. However, the RAISE app recommended $30 \mathrm{~min}$ of cardiorespiratory exercise daily (equivalent to 210 min per week), which is in excess of the minimum weekly PA recommendations.

The Rheumatoid arthritis diet—-to ease pain app was primarily focused on providing dietary advice but also recommended all types of PA. It was rated as partially adhering to the guidance because PA dosages were not specified.

Table 4. Congruence with evidence-informed recommendations in mobile apps targeting physical activity in people with rheumatoid arthritis.

\begin{tabular}{lllll}
\hline $\begin{array}{l}\text { Physical activity and exercise recommen- } \\
\text { dations }\end{array}$ & Knee pain relieving exercises & $\begin{array}{l}\text { Rheumatoid arthritis diet - to ease } \\
\text { pain }\end{array}$ & RAISE $^{\mathrm{a}}$ & Paddison program $^{\text {Partial }}$ \\
\hline Cardiorespiratory exercise & No & Partia & Yes & No \\
Resistance exercise & Partial & Partial & Yes & Partial \\
Flexibility exercise & Partial & Partial & Yes & No \\
Neuromotor exercise & No & Partial & Yes & Partial \\
\hline
\end{tabular}

${ }^{\mathrm{a}}$ RAISE: Rheumatoid Arthritis Information Support and Education.

Completeness of exercise reporting in apps using CERT is summarized in Table 5. All apps offered information on the (1) exercise format (individual, unsupervised, or home-based), (2) the potential positive benefits of exercise as a motivational strategy, and (3) nonexercise advice (eg, lifestyle or medication). All apps specified some form of guidance for exercise progression, although the parameters for exercise progression did not always align with guidance. All apps, except Rheumatoid arthritis diet - to ease pain, provided details of (1) the exercise equipment required; (2) the qualification/training of the exercise instructor; and (3) descriptions, adaptations, and dosage of the exercises. Two apps offered decision rules to help users determine an initial exercise dose (RAISE and Paddison program). One app (RAISE) offered the option to document exercise adherence.

The RAISE app reported all types of PA completely and achieved the maximum possible score (14 out of 14). The Rheumatoid arthritis diet - to ease the pain app achieved the lowest CERT score (7 out of 14), predominantly because it did not explicitly report PA dosages. Interrater reliability for CERT scoring was good (ICC 0.796; 95\% CI 0.806-0.933). 
Table 5. Physical activity and exercise reporting in accordance with the Consensus of Exercise Reporting Template in mobile apps targeting physical activity in people with rheumatoid arthritis.

\begin{tabular}{|c|c|c|c|c|}
\hline Items and item number & Knee pain relieving exercises & Rheumatoid arthritis diet- to ease pain & RAISE $^{\mathrm{a}}$ & Paddison program \\
\hline \multicolumn{5}{|l|}{ What } \\
\hline 1 & Yes & No & Yes & Yes \\
\hline \multicolumn{5}{|l|}{ Who } \\
\hline 2 & Yes & No & Yes & Yes \\
\hline \multicolumn{5}{|l|}{ How } \\
\hline 3 & Yes & Yes & Yes & Yes \\
\hline 4 & Yes & Yes & Yes & Yes \\
\hline 5 & No & No & Yes & No \\
\hline 6 & Yes & Yes & Yes & Yes \\
\hline 7 & Yes & Yes & Yes & Yes \\
\hline 8 & Yes & No & Yes & Yes \\
\hline 9 & Yes & No & Yes & Yes \\
\hline 10 & Yes & Yes & Yes & Yes \\
\hline 11 & $\mathrm{~N} / \mathrm{A}^{\mathrm{b}}$ & N/A & N/A & N/A \\
\hline \multicolumn{5}{|l|}{ Where } \\
\hline 12 & Yes & Yes & Yes & Yes \\
\hline \multicolumn{5}{|l|}{ When and how much } \\
\hline 13 & Yes & No & Yes & No \\
\hline \multicolumn{5}{|l|}{ Tailoring } \\
\hline 14 & Yes; tailored & Yes; generic & Yes; tailored & Yes; tailored \\
\hline 15 & No & No & Yes & Yes \\
\hline \multicolumn{5}{|l|}{ How well } \\
\hline 16 & N/A & N/A & N/A & N/A \\
\hline Total Score & 12 & 7 & 14 & 12 \\
\hline
\end{tabular}

${ }^{a}$ RAISE: Rheumatoid Arthritis Information Support and Education.

${ }^{\mathrm{N}} \mathrm{N} / \mathrm{A}$ : not applicable.

The apps included between 3 (Rheumatoid arthritis diet-to ease pain) and 7 (RAISE and Paddison program) BCTs. Two BCTs were identified in all apps (instructions on how to perform behavior and information about health consequences; Table 6). Credible source was present in all apps but the Paddison program. All apps included demonstration of behavior apart from the Rheumatoid arthritis diet— to ease pain app. The
RAISE and Paddison program apps both included 7 BCTs. Five of these BCTs were common to both apps (instruction on how to perform behavior, information about health consequences, demonstration of behavior, goal setting, and social comparison). Only the RAISE app included self-monitoring of behavior. The interrater reliability for BCTs was good (ICC 0.874; 95\% CI 0.799-0.921). 
Table 6. Behavior change techniques included in mobile apps targeting physical activity in people with rheumatoid arthritis.

\begin{tabular}{|c|c|c|c|c|}
\hline Behavior change techniques & Knee pain relieving exercises & $\begin{array}{l}\text { Rheumatoid arthritis diet— to ease } \\
\text { pain }\end{array}$ & RAISE $^{\mathrm{a}}$ & Paddison program \\
\hline $\begin{array}{l}\text { Instruction on how to perform behav- } \\
\text { ior }\end{array}$ & Yes & Yes & Yes & Yes \\
\hline $\begin{array}{l}\text { Information about health conse- } \\
\text { quences }\end{array}$ & Yes & Yes & Yes & Yes \\
\hline Demonstration of behavior & Yes & No & Yes & Yes \\
\hline Credible source & Yes & Yes & Yes & No \\
\hline Goal setting behavior & No & No & Yes & Yes \\
\hline Social comparison & No & No & Yes & Yes \\
\hline Graded task & Yes & No & No & Yes \\
\hline Self-monitoring behavior & No & No & Yes & No \\
\hline Generalization of target behavior & No & No & No & Yes \\
\hline Framing/reframing & No & No & No & Yes \\
\hline Total number & 5 & 3 & 7 & 7 \\
\hline
\end{tabular}

${ }^{\mathrm{a}}$ RAISE: Rheumatoid Arthritis Information Support and Education.

\section{Discussion}

\section{Principal Findings}

This is the first systematic identification, quality appraisal, and content analysis of widely available PA and exercise apps for people with RA. Up to June 20, 2019, there were only 4 unique apps that met our inclusion criteria available on $\mathrm{iOS}$ and/or Android platforms. The quality and content of the included apps varied considerably and did not always align with PA recommendations. Notably, higher-quality apps tended to include a greater number of BCTs and most closely aligned to PA recommendations. The highest quality app (RAISE) was the only app to explicitly report PA prescriptions aligned to evidence-informed recommendations for people with RA and embedded the highest number of BCTs.

Despite guidance for the development and evaluation of mobile apps $[25,40]$, the quality ratings of the apps included in our review were mixed. This finding is consistent with reviews of publicly available rheumatology self-management apps [20-22] and apps targeting PA and exercise in the general population [41,42]. For example, Simoes et al [43] identified 51 moderate-quality PA apps for use by the general population (MARS total score 3.16 to 4.41 ) with the functionality and esthetics domains scoring most highly. This is broadly similar to our findings and suggests that the included apps were intuitive, logical to follow, easy to learn and navigate, which is particularly important for people with RA who may have fatigue or hand and wrist disability $[44,45]$. However, the apps achieved lower ratings for information quality and engagement and to optimize utility, app content should be high quality, interesting, simple to understand, and have the option to be tailored with user data [25].

The RAISE app was the only app that fully and explicitly reported PA prescription that aligned to all evidence-informed recommendations for people with RA. This may be because the
RAISE app was the only app to be developed in conjunction with both clinicians and people with RA; thus, concordance with evidence-based guidelines and the acceptability and user experience of people with RA were likely to be considered from inception.

Even though the RAISE app was rated as congruent with all PA guidance, it recommended a weekly duration of cardiorespiratory PA in excess of the minimum dosage stated in the guidelines, which may be inappropriate for novice exercisers with RA. Interestingly, the RAISE app had the lowest number of installs and number of user ratings, suggesting that it is not widely used by people with RA. This may be because people with RA were unaware of the app or because they found the PA recommendations to be too ambitious and unacceptable.

The other apps did not completely align with PA recommendations, similar to other research [41,42]. Common reasons for apps not completely adhering to the PA guidance were the lack of or incorrect specific PA dosages (eg, sets, repetitions). For example, the Rheumatoid arthritis diet-to ease pain app recommended all PA types but did not provide specific PA dosages so was only partially congruent with the guidance. This may be because the primary focus of this app was dietary advice.

PA prescription may need to be modified for people with RA $[3,4,6]$ and some apps offered a reduced starting dose or suggested ways to tailor exercises or exercise progression. However, these recommendations did not always align with guidance. Incomplete or unclear PA prescriptions maybe confusing to users who are novice exercisers, and inappropriate prescriptions may impact users' engagement and adherence with PA and compromise PA effectiveness or safety [7].

All apps included some BCTs that may promote adherence to PA, and the higher-quality apps included a greater number of BCTs. No app contained more than 7 BCTs, which is similar to the findings of reviews of apps targeting PA in the general 
population $[41,43,46,47]$. Although the optimum number of BCTs needed to support PA adherence is not known, a recent systematic review including 8 randomized controlled trials (1018 participants) found that interventions with less than 7 BCTs were most effective at enhancing adherence to exercise in people with persistent musculoskeletal pain [48]. In addition, there was a moderate level of evidence that 5 BCTs (social support [unspecified], goal setting [behavior], instruction of behavior, demonstration of behavior, and behavior practice/rehearsal) supported PA adherence [48]. Two of the higher-quality apps in our review included 3 of these 5 BCTs adding evidence-based integrity, although the effectiveness of these apps has not been investigated.

\section{Methodological Considerations}

The strengths of this review include the comprehensive search of both the UK Google Play Store and Apple App Store. This was complemented by a search of the United Kingdom National Health Service app library and the Apple App Store in the United States, Canada, New Zealand, and Australia. No new apps were identified, suggesting that all English language apps were captured. However, this review only focuses on publicly available apps for use by people with RA, so we may not have captured apps primarily designed for research.

Where possible, we followed rigorous processes that were aligned to PRISMA guidelines [30]. Two reviewers independently screened identified apps for eligibility, extracted data, and rated the quality and content of the apps using standardized tools. Interrater reliability was good or excellent, which lends confidence to our findings. App quality was assessed with the widely used MARS $[21,22,26]$. However, the MARS rating is subjective, and people with RA may have different perceptions of the app features to our assessors, who did not have RA.

Notably, it is possible to reset star ratings in the iOS app store when new app versions are released. It is not known if the star ratings extracted at the time of our appraisal refer to overall or current app versions ratings. However, all included apps have limited versions, so the impact of this on our findings is likely to be minimal. Finally, no evaluation of the content of the privacy policies of included apps was completed, so we do not know whether the policy adequately protects users' rights.

This comprehensive review of PA apps for people with RA identified 4 apps of mixed quality and content. Higher quality apps more closely aligned to PA guidance and included a greater number of BCTs previously shown to promote PA. The RAISE app was the highest quality app. Future apps should be rigorously developed with key stakeholders, and include evidence-based PA guidance and BCTs, to optimize their acceptability and impact on PA. Robustly designed research into the effect of apps on PA adherence is crucial before implementation.

\section{Authors' Contributions}

LMB wrote the draft manuscript. All authors discussed the draft and provided comments and suggestions for change. All authors approved the final report.

\section{Conflicts of Interest}

None declared.

\section{References}

1. Abhishek A, Doherty M, Kuo C, Mallen CD, Zhang W, Grainge MJ. Rheumatoid arthritis is getting less frequent-results of a nationwide population-based cohort study. Rheumatology (Oxford) 2017 May 01;56(5):736-744 [FREE Full text] [doi: 10.1093/rheumatology/kew468] [Medline: 28064207]

2. Hunter TM, Boytsov NN, Zhang X, Schroeder K, Michaud K, Araujo AB. Prevalence of rheumatoid arthritis in the United States adult population in healthcare claims databases, 2004-2014. Rheumatol Int 2017 Sep;37(9):1551-1557. [doi: 10.1007/s00296-017-3726-1] [Medline: 28455559]

3. Osthoff AR, Niedermann K, Braun J, Adams J, Brodin N, Dagfinrud H, et al. 2018 EULAR recommendations for physical activity in people with inflammatory arthritis and osteoarthritis. Ann Rheum Dis 2018 Sep;77(9):1251-1260. [doi: 10.1136/annrheumdis-2018-213585] [Medline: 29997112]

4. Garber CE, Blissmer B, Deschenes MR, Franklin BA, Lamonte MJ, Lee I, American College of Sports Medicine. American college of sports medicine position stand quantity and quality of exercise for developing and maintaining cardiorespiratory, musculoskeletal, and neuromotor fitness in apparently healthy adults: guidance for prescribing exercise. Med Sci Sports Exerc 2011 Jul;43(7):1334-1359. [doi: 10.1249/MSS.0b013e318213fefb] [Medline: 21694556]

5. World Health Organization. Global recommendations on physical activity for health. In: World Health Organization Report. Switzerland: World Health Organization Press; 2010:1-58.

6. Nelson ME, Rejeski WJ, Blair SN, Duncan PW, Judge JO, King AC, et al. Physical activity and public health in older adults: recommendation from the American college of sports medicine and the American heart association. Med Sci Sports Exerc 2007 Aug;39(8):1435-1445. [doi: 10.1249/mss.0b013e3180616aa2] [Medline: 17762378]

7. Slade S, Dionne CE, Underwood M, Buchbinder R, Beck B, Bennell K, et al. Consensus on exercise reporting template (CERT): modified Delphi study. Phys Ther 2016 Oct;96(10):1514-1524. [doi: 10.2522/ptj.20150668] [Medline: 27149962] 
8. Sokka T, Häkkinen A, Kautiainen H, Maillefert JF, Toloza S, Hansen TM, QUEST-RA Group. Physical inactivity in patients with rheumatoid arthritis: data from twenty-one countries in a cross-sectional, international study. Arthritis Rheum 2008 Jan 15;59(1):42-50 [FREE Full text] [doi: 10.1002/art.23255] [Medline: 18163412]

9. Manning VL, Hurley MV, Scott DL, Bearne LM. Are patients meeting the updated physical activity guidelines? Physical activity participation, recommendation, and preferences among inner-city adults with rheumatic diseases. J Clin Rheumatol 2012 Dec;18(8):399-404. [doi: 10.1097/RHU.0b013e3182779cb6] [Medline: 23188205]

10. van Zanten JJ, Rouse PC, Hale ED, Ntoumanis N, Metsios GS, Duda JL, et al. Perceived barriers, facilitators and benefits for regular physical activity and exercise in patients with rheumatoid arthritis: a review of the literature. Sports Med 2015 Oct;45(10):1401-1412 [FREE Full text] [doi: 10.1007/s40279-015-0363-2] [Medline: 26219268]

11. Bearne LM, Manning VL, Choy E, Scott DL, Hurley MV. Participants' experiences of an education, self-management and upper extremity exercise training for people with rheumatoid arthritis programme (EXTRA). Physiotherapy 2017 Dec;103(4):430-438. [doi: 10.1016/j.physio.2016.12.002] [Medline: 28823567]

12. Thomsen T, Aadahl M, Beyer N, Hetland ML, Løppenthin K, Midtgaard J, et al. The efficacy of motivational counselling and SMS reminders on daily sitting time in patients with rheumatoid arthritis: a randomised controlled trial. Ann Rheum Dis 2017 Sep;76(9):1603-1606 [FREE Full text] [doi: 10.1136/annrheumdis-2016-210953] [Medline: 28584189]

13. Knittle K, de Gucht V, Hurkmans E, Peeters A, Ronday K, Maes S, et al. Targeting motivation and self-regulation to increase physical activity among patients with rheumatoid arthritis: a randomised controlled trial. Clin Rheumatol 2015 Feb;34(2):231-238. [doi: 10.1007/s10067-013-2425-x] [Medline: 24213780]

14. Manning VL, Hurley MV, Scott DL, Coker B, Choy E, Bearne LM. Education, self-management, and upper extremity exercise training in people with rheumatoid arthritis: a randomized controlled trial. Arthritis Care Res (Hoboken) 2014 Feb;66(2):217-227 [FREE Full text] [doi: 10.1002/acr.22102] [Medline: 23925924]

15. Ndosi M, Ferguson R, Backhouse MR, Bearne L, Ainsworth P, Roach A, et al. National variation in the composition of rheumatology multidisciplinary teams: a cross-sectional study. Rheumatol Int 2017 Sep;37(9):1453-1459 [FREE Full text] [doi: 10.1007/s00296-017-3751-0] [Medline: 28551723]

16. British SOR. National Early Inflammatory Arthritis Audit (NEIAA) 1st Annual Report. In: British Society of Rheumatology. -: British Society of Rheumatology; Oct 2019:1-51.

17. McCuish WJ, Bearne LM. Do inpatient multidisciplinary rehabilitation programmes improve health status in people with long-term musculoskeletal conditions? A service evaluation. Musculoskeletal Care 2014 Dec;12(4):244-250. [doi: 10.1002/msc.1072] [Medline: 24840767]

18. Silva BM, Rodrigues JJ, de la Torre Díez I, López-Coronado M, Saleem K. Mobile-health: a review of current state in 2015. J Biomed Inform 2015 Aug;56:265-272 [FREE Full text] [doi: 10.1016/j.jbi.2015.06.003] [Medline: 26071682]

19. Najm A, Gossec L, Weill C, Benoist D, Berenbaum F, Nikiphorou E. Mobile health apps for self-management of rheumatic and musculoskeletal diseases: systematic literature review. JMIR Mhealth Uhealth 2019 Nov 26;7(11):e14730 [REE Full text] [doi: 10.2196/14730] [Medline: 31769758]

20. Luo D, Wang P, Lu F, Elias J, Sparks JA, Lee YC. Mobile apps for individuals with rheumatoid arthritis: a systematic review. J Clin Rheumatol 2019 Apr;25(3):133-141. [doi: 10.1097/RHU.0000000000000800] [Medline: 29933327]

21. Knitza J, Tascilar K, Messner E, Meyer M, Vossen D, Pulla A, et al. German mobile apps in rheumatology: review and analysis using the mobile application rating scale (MARS). JMIR Mhealth Uhealth 2019 Aug 05;7(8):e14991 [FREE Full text] [doi: 10.2196/14991] [Medline: 31381501]

22. Grainger R, Townsley H, White B, Langlotz T, Taylor WJ. Apps for people with rheumatoid arthritis to monitor their disease activity: a review of apps for best practice and quality. JMIR Mhealth Uhealth 2017 Feb 21;5(2):e7 [FREE Full text] [doi: 10.2196/mhealth.6956] [Medline: 28223263]

23. Bhattarai P, Newton-John TR, Phillips JL. Quality and usability of arthritic pain self-management apps for older adults: a systematic review. Pain Med 2018 Mar 01;19(3):471-484. [doi: 10.1093/pm/pnx090] [Medline: 28541464]

24. Griffiths AJ, White CM, Thain PK, Bearne LM. The effect of interactive digital interventions on physical activity in people with inflammatory arthritis: a systematic review. Rheumatol Int 2018 Sep;38(9):1623-1634 [FREE Full text] [doi: 10.1007/s00296-018-4010-8] [Medline: 29556750]

25. Najm A, Nikiphorou E, Kostine M, Richez C, Pauling JD, Finckh A, et al. EULAR points to consider for the development, evaluation and implementation of mobile health applications aiding self-management in people living with rheumatic and musculoskeletal diseases. RMD Open 2019;5(2):e001014 [FREE Full text] [doi: 10.1136/rmdopen-2019-001014] [Medline: $\underline{31565245]}$

26. Stoyanov SR, Hides L, Kavanagh DJ, Zelenko O, Tjondronegoro D, Mani M. Mobile app rating scale: a new tool for assessing the quality of health mobile apps. JMIR Mhealth Uhealth 2015 Mar 11;3(1):e27 [FREE Full text] [doi: 10.2196/mhealth.3422] [Medline: 25760773]

27. Michie S, Richardson M, Johnston M, Abraham C, Francis J, Hardeman W, et al. The behavior change technique taxonomy (v1) of 93 hierarchically clustered techniques: building an international consensus for the reporting of behavior change interventions. Ann Behav Med 2013 Aug;46(1):81-95. [doi: 10.1007/s12160-013-9486-6] [Medline: 23512568]

28. American College Of Sports Medicine. ACSMs Guidelines for Exercise Testing and Prescription. Netherlands: Wolters Kluwer; Feb 10, 2017. 
29. Slade SC, Dionne CE, Underwood M, Buchbinder R. Consensus on exercise reporting template (CERT): explanation and elaboration statement. Br J Sports Med 2016 Dec;50(23):1428-1437. [doi: 10.1136/bjsports-2016-096651] [Medline: $\underline{27707738]}$

30. Liberati A, Altman DG, Tetzlaff J, Mulrow C, Gøtzsche PC, Ioannidis JP, et al. The PRISMA statement for reporting systematic reviews and meta-analyses of studies that evaluate healthcare interventions: explanation and elaboration. $\mathrm{Br}$ Med J 2009 Jul 21;339:b2700 [FREE Full text] [doi: 10.1136/bmj.b2700] [Medline: 19622552]

31. Mack J, Mack R. fnd. 2014. URL: https://fnd.io/ [accessed 2019-06-19]

32. Sekhon M, White C, Amirova A, Godfrey E, Revenas A, Bearne L. Effectiveness of web-based and mobile health interventions designed to support adherence to physical activity for people with inflammatory arthritis: a systematic review. PROSPERO International prospective register of systematic reviews. United Kingdom: University of York; 2019. URL: https://www.crd.york.ac.uk/prospero/display record.php?ID=CRD42019129341 [accessed 2020-05-08]

33. Breitenstein SM, Gross D, Garvey CA, Hill C, Fogg L, Resnick B. Implementation fidelity in community-based interventions. Res Nurs Health 2010 Apr;33(2):164-173 [FREE Full text] [doi: 10.1002/nur.20373] [Medline: 20198637]

34. Godfrey E, Wileman V, Galea Holmes M, McCracken LM, Norton S, Moss-Morris R, et al. Physical therapy informed by acceptance and commitment therapy (PACT) versus usual care physical therapy for adults with chronic low back pain: a randomized controlled trial. J Pain 2019 Jun 05 [FREE Full text] [doi: 10.1016/j.jpain.2019.05.012] [Medline: 31173921]

35. Bearne L, Galea Holmes M, Bieles J, Eddy S, Fisher G, Modarai B, et al. Motivating structured walking activity in people with intermittent claudication (MOSAIC): protocol for a randomised controlled trial of a physiotherapist-led, behavioural change intervention versus usual care in adults with intermittent claudication. BMJ Open 2019 Aug 24;9(8):e030002 [FREE Full text] [doi: 10.1136/bmjopen-2019-030002] [Medline: 31446416]

36. Slade SC, Finnegan S, Dionne CE, Underwood M, Buchbinder R. The consensus on exercise reporting template (CERT) applied to exercise interventions in musculoskeletal trials demonstrated good rater agreement and incomplete reporting. $\mathrm{J}$ Clin Epidemiol 2018 Nov;103:120-130. [doi: 10.1016/j.jclinepi.2018.07.009] [Medline: 30055247]

37. Huston N. Mobile Application Rating Scale Training Module 2.: Daily Motion; 2015. URL: $\underline{\text { https://www.dailymotion.com/ }}$ video/x3443jz [accessed 2019-06-20]

38. Michie S, Wood CE, Johnston M, Abraham C, Francis JJ, Hardeman W. Behaviour change techniques: the development and evaluation of a taxonomic method for reporting and describing behaviour change interventions (a suite of five studies involving consensus methods, randomised controlled trials and analysis of qualitative data). Health Technol Assess 2015 Nov;19(99):1-188 [FREE Full text] [doi: 10.3310/hta19990] [Medline: 26616119]

39. Koo TK, Li MY. A guideline of selecting and reporting intraclass correlation coefficients for reliability research. J Chiropr Med 2016 Jun;15(2):155-163 [FREE Full text] [doi: 10.1016/j.jcm.2016.02.012] [Medline: 27330520]

40. National Institute for Health and Care Excellence. Evidence standards framework for digital health technologies. National Institute for Health and Care Excellence. United Kingdom; 2019 Mar. URL: https://www.nice.org.uk/Media/Default/About/ what-we-do/our-programmes/evidence-standards-framework/digital-evidence-standards-framework.pdf [accessed 2020-06-18]

41. Kebede M, Steenbock B, Helmer SM, Sill J, Möllers T, Pischke CR. Identifying evidence-informed physical activity apps: content analysis. JMIR Mhealth Uhealth 2018 Dec 18;6(12):e10314 [FREE Full text] [doi: 10.2196/10314] [Medline: 30563810]

42. Knight E, Stuckey MI, Prapavessis H, Petrella RJ. Public health guidelines for physical activity: is there an app for that? A review of android and apple app stores. JMIR Mhealth Uhealth 2015 May 21;3(2):e43 [FREE Full text] [doi: 10.2196/mhealth.4003] [Medline: 25998158]

43. Simões P, Silva AG, Amaral J, Queirós A, Rocha NP, Rodrigues M. Features, behavioral change techniques, and quality of the most popular mobile apps to measure physical activity: systematic search in app stores. JMIR Mhealth Uhealth 2018 Oct 26;6(10):e11281 [FREE Full text] [doi: 10.2196/11281] [Medline: 30368438]

44. Bearne LM, Coomer AF, Hurley MV. Upper limb sensorimotor function and functional performance in patients with rheumatoid arthritis. Disabil Rehabil 2007 Jul 15;29(13):1035-1039. [doi: 10.1080/09638280600929128] [Medline: 17612988]

45. Primdahl J, Hegelund A, Lorenzen AG, Loeppenthin K, Dures E, Appel Esbensen B. The experience of people with rheumatoid arthritis living with fatigue: a qualitative metasynthesis. BMJ Open 2019 Mar 20;9(3):e024338 [FREE Full text] [doi: 10.1136/bmjopen-2018-024338] [Medline: 30898808]

46. Bondaronek P, Alkhaldi G, Slee A, Hamilton FL, Murray E. Quality of publicly available physical activity apps: review and content analysis. JMIR Mhealth Uhealth 2018 Mar 21;6(3):e53 [FREE Full text] [doi: 10.2196/mhealth.9069] [Medline: 29563080]

47. Middelweerd A, Mollee JS, van der Wal CN, Brug J, te Velde SJ. Apps to promote physical activity among adults: a review and content analysis. Int J Behav Nutr Phys Act 2014 Jul 25;11:97 [FREE Full text] [doi: 10.1186/s12966-014-0097-9] [Medline: 25059981]

48. Meade LB, Bearne LM, Sweeney LH, Alageel SH, Godfrey EL. Behaviour change techniques associated with adherence to prescribed exercise in patients with persistent musculoskeletal pain: systematic review. Br J Health Psychol 2019 Feb;24(1):10-30 [FREE Full text] [doi: 10.1111/bjhp.12324] [Medline: 29911311] 


\begin{abstract}
Abbreviations
BCT: behavior change technique

BCTT: Behavior Change Technique Taxonomy

CERT: Consensus on Exercise Reporting Template

ICC: intraclass correlation coefficient

MARS: mobile app rating scale

PA: physical activity

PRISMA: Preferred Reporting Items for Systematic Review and Meta-Analyses

PROSPERO: International Prospective Register of Systematic Reviews

RA: rheumatoid arthritis

RAISE: Rheumatoid Arthritis Information Support and Education
\end{abstract}

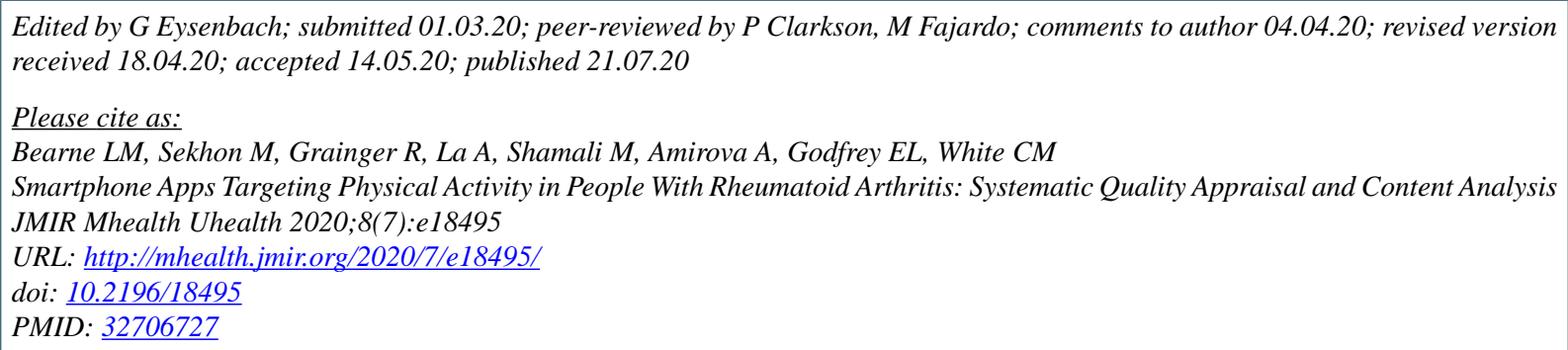

OLindsay M Bearne, Mandeep Sekhon, Rebecca Grainger, Anthony La, Mehrdad Shamali, Aliya Amirova, Emma L Godfrey, Claire M White. Originally published in JMIR mHealth and uHealth (http://mhealth.jmir.org), 21.07.2020. This is an open-access article distributed under the terms of the Creative Commons Attribution License (https://creativecommons.org/licenses/by/4.0/), which permits unrestricted use, distribution, and reproduction in any medium, provided the original work, first published in JMIR mHealth and uHealth, is properly cited. The complete bibliographic information, a link to the original publication on http://mhealth.jmir.org/, as well as this copyright and license information must be included. 